BMJ

Paediatrics

Open

\section{Interdisciplinary handover between obstetric nursing and neonatal physician teams: an observational study}

Anshul Arora, ${ }^{\oplus 1}$ Thomas Kannampallil, ${ }^{2}$ Joanna Abraham ${ }^{2}$
To cite: Arora A, Kannampallil T, Abraham J. Interdisciplinary handover between obstetric nursing and neonatal physician teams: an observational study. BMJ Paediatrics Open 2019;3:e000432. doi:10.1136/ bmjpo-2018-000432

- Additional material is published online only. To view please visit the journal online (http://dx.doi.org/10.1136/ bmjpo-2018-000432).

Received 30 December 2018 Revised 12 February 2019 Accepted 9 March 2019

\section{Check for updates}

(c) Author(s) (or their employer(s)) 2019. Re-use permitted under CC BY-NC. No commercial re-use. See rights and permissions. Published by BMJ.

${ }^{1}$ Department of Pediatrics, University of Illinois at Chicago College of Medicine, Chicago, Illinois, USA

${ }^{2}$ Department of Anesthesiology, School of Medicine, Washington University in St Louis, St Louis, Missouri, USA

\section{Correspondence to}

Dr Joanna Abraham, Department of Anesthesiology, School of Medicine, Washington University in St Louis, St Louis M0 63110, USA; joannaa@wustl.edu

\section{ABSTRACT}

Objective We investigated the content and quality of communication of interservice interprofessional handover between obstetric nurses and neonatal physicians for high-risk deliveries.

Design Observational study.

Setting Labour and delivery unit at a tertiary care hospital.

Method We audio-recorded handovers between obstetric and neonatal teams $(n=50)$ and conducted clinician interviews $(n=29)$. A handover content framework was developed and used to qualitatively code missing core and ancillary content and their potential for adverse events. Results $26(52 \%)$ handovers missed one or more clinical content elements; a third of the handovers missed at least one core clinical content element. Increase in the number of missed clinical content elements increased the odds of potential adverse events by 2.39 (95\% Cl1.18 to 5.37 ). Both residents and nurses perceived handovers to be of low quality and inconsistent and attributed it to the lack of a structured handover process.

Conclusion Streamlining handover processes by instituting standardisation approaches for both information organisation and communication can improve the quality of neonatal handovers.

\section{INTRODUCTION}

Handovers (also referred to as handoffs) serve as an interactive forum for the transfer of information, responsibility and authority between clinicians. ${ }^{1}$ Handovers occur at different points in the care delivery process: at routine shift changes and at non-routine service or location changes. ${ }^{2}$ Although handovers are instrumental for care continuity, evidence suggests that they are a source for medical errors. ${ }^{3}$

Compared with shift-based handovers, challenges are exacerbated in interservice interprofessional handovers (eg, emergency nurse and medicine resident) because of the differences in clinical expertise, professional backgrounds and varying roles. ${ }^{4-6}$ One such commonly occurring handover is between obstetric (OB) nurses and the neonatal physicians for high-risk deliveries. Nearly $10 \%$ of all deliveries in the USA require an

\section{What is already known on this topic?}

- Neonatal handovers are a unique example of interprofessional interservice handovers between obstetric nurses and neonatal physicians for high-risk deliveries.

- These exchanges are often ad hoc, lack structure and are prone to errors.

\section{What this study hopes to add?}

We identified missing core clinical elements, with each additional missed element increasing the potential for adverse events nearly twofold.

- Opportunities for improving the neonatal handover process includes standardising the content and associated workflow process.

intervention from a neonatologist; $1 \%$ of newborns require extensive resuscitation support from a neonatal intensive care unit (NICU) team at delivery. ${ }^{7}$ As such, these handovers are complex and vulnerable to safety threats affecting care and management needs and demands of both the mother and the newborn. ${ }^{8-10}$

We investigated the following research questions: (A) what is the nature of clinical content exchanged during $\mathrm{OB}$ nurse to NICU physician handover communication?; (B) what is the core clinical content that is discussed? What is missed? What is the potential for missed clinical content for causing adverse outcomes?; and (C) what are OB nurses' and NICU physicians' perceptions regarding the quality and effectiveness of handover communication?

\section{METHOD}

Study setting and participants

This study was conducted in the Labor and Delivery (L\&D) unit at the University of Illinois Hospital and Health Science Center. The L\&D unit performs approximately 2700 
deliveries and cares for all pregnant patients in labour including prematurity or any complex maternal or fetal medical conditions as described in the American Academy of Pediatrics Manual. ${ }^{11}$

Study participants included fellows, residents and nurses from the $\mathrm{OB}$ and neonatal teams. The OB team works in the L\&D unit and comprises 2 attending physicians, 4 OB residents, 2 family medicine residents, 1-2 midwives, and $8-10$ OB nurses. The neonatal team consists of one NICU attending physician, one neonatology fellow, one paediatric-neonatal resident (postgraduate year 2 or 3 ) and one paediatric intern. Four neonatology fellows, 25 paediatric residents and $4 \mathrm{OB}$ nurses participated in the study over a 6 -month period.

\section{Patient involvement}

There was no direct patient involvement in this study.

\section{Neonatal handovers}

Neonatal handovers involve the communication of patient-related information between the OB nursing team and the neonatal team. Neonatal handover process is initiated when an $\mathrm{OB}$ nurse contacts a neonatology fellow for assistance in a high-risk delivery. The fellow coordinates with the paediatric-neonatal resident(s) and meets the $\mathrm{OB}$ team (OB nurse, $\mathrm{OB}$ resident(s) and $\mathrm{OB}$ attending) in the $\mathrm{L} \& \mathrm{D}$ room. An OB nurse then provides a verbal handover to the paediatric-neonatal resident (ie, neonatal handover). This handover includes clinical content related to maternal obstetric history (age, gestational age, lab results, imaging and medications), medical history and pregnancy history (any intrapartum events, rupture of membrane, colour of amniotic fluid, chorioamnionitis, fetal tachycardia or bradycardia). These handovers often follow a narrative format, with each OB nurse following their own conversational style and structure. For example, some nurses used personalised handwritten notes, whereas others used an antepartum assessment sheet as a guide for their handover discussion.

After the handover, the antepartum assessment sheet is provided to the neonatal team. The antepartum assessment sheet, generated from the electronic health record and completed by the mother's admitting nurse, contains information related to maternal age, gestational age, labs and other relevant information.

Postdelivery, the neonatal team performs resuscitation and stabilisation activities for the newborn, as necessary. Depending on the clinical status of the newborn, decisions regarding the transfer of the newborn to the NICU are also made. Paediatric residents with the neonatal team then create a 'delivery note' in the newborn's chart with updated information regarding labs, resuscitation events, Apgar scores and the newborn's disposition. This delivery note includes maternal information obtained at the time of delivery handover, information gathered after accessing mother's patient record and resuscitation events performed in the delivery room.

\section{Data collection}

Data collection methods included general observations, clinician shadowing, semistructured interviews and audio recording of neonatal handover communication.

We conducted approximately 20 hours of observation taking detailed field notes to develop a general understanding of clinical workflow of the $\mathrm{OB}$ and neonatal teams. These sessions focused on observing the general coordination, decision-making and communication processes and tasks performed by both teams (conducted by the first author).

We shadowed the $\mathrm{OB}$ and neonatal teams during neonatal handovers to obtain insights on how the $\mathrm{OB}$ nurse requested neonatal consulting service, artefacts used for neonatal handovers (by the OB team) and team interactions. We shadowed 50 neonatal handovers, which involved 4 OB nurses and 29 neonatal team members (neonatal fellows $[n=4]$ and paediatric residents $[n=25]$ ).

During these shadowing sessions, we audio-recorded a convenience sample of $50 \quad(n=50)$ neonatal handovers between the $\mathrm{OB}$ and neonatal team. After each handover, we also collected the associated, deidentified antepartum assessment sheets and the resident delivery notes $(n=50)$.

\section{Semistructured interviews}

We conducted semistructured interviews with paediatric residents $(n=12)$ and $\mathrm{OB}$ nurses $(n=3)$. Separate interview guides were used for residents and nurses (see online supplementary appendix 1). Resident interviews focused on gathering perceptions regarding the neonatal handover process, completeness and quality of maternal information provided by the $\mathrm{OB}$ team and potential suggestions for improving the handover process. Nurse interviews focused on the following: ease of data gathering for handover, existing tools and sources, perceptions of an effective handover, identified barriers and suggestions to improve the neonatal handover processes.

\section{Data coding and analysis}

Qualitative coding

Observation and shadowing data were coded using an open coding approach ${ }^{12}$ to identify OB and NICU team workflows. Examples of workflow processes included roles and responsibilities, handover activities, decisions made during handovers, workflow dependencies, artefacts used, communication challenges and information presentation strategies.

All audio-recorded verbal handovers were deidentified and transcribed verbatim for further analysis. Verbal communication for each handover was segmented into functional units called utterances. Utterances are psychological analogues of a single unit of experience including statements, commands and single words (eg, 'okay'). ${ }^{513}$

Our modified clinical content framework comprised the following data elements: mother's antepartum history, intrapartum and delivery course (table 1 ). The clinical content framework was developed in three phases. In the first phase, using a validated labour and delivery checklist 
Table 1 Clinical content framework for neonatal handovers (core content elements are represented in bold)

\begin{tabular}{ll}
\hline $\begin{array}{l}\text { Patient } \\
\text { history }\end{array}$ & Handoff elements \\
\hline Antepartum & $\begin{array}{l}\text { Age, gestational age, gravida/para, multiple } \\
\text { gestation, blood type, rhogam status, } \\
\text { genetic studies and sonographic findings. }\end{array}$ \\
\hline Intrapartum & $\begin{array}{l}\text { GBS (Group B Streptococcus), RPR, rubella, } \\
\text { HIV/hepatitis B, chorioamnionitis, position } \\
\text { of the baby, size of the baby, biophysical } \\
\text { profile, maternal diabetes, maternal drug/ } \\
\text { urine toxicology, steroid status, maternal } \\
\text { drug status, medications and psychiatric } \\
\text { history. }\end{array}$ \\
\hline $\begin{array}{l}\text { Type of delivery, induction, reason for } \\
\text { induction, reason for C-section, rupture } \\
\text { of membrane time and type, colour } \\
\text { of amniotic fluid, reason for NICU } \\
\text { attendance and fetal heart rate/tracing. }\end{array}$ \\
\hline
\end{tabular}

NICU, neonatal intensive care unit.

for interdisciplinary communication, ${ }^{14} 15$ we created an initial list of clinical elements that were pertinent for characterising neonatal care continuity. Using this initial but comprehensive list of clinical content elements, an interdisciplinary team of practising clinicians from L\&D and neonatal units used a consensus-driven approach to review and modify the initial list of clinical elements. This review and revision were based on the relevance, priority and importance of the clinical elements for neonatal care continuity. Finally, during the third phase, medical and nursing directors and managers of L\&D and neonatal units participated in collaborative discussions to finalise and categorise these elements as core and ancillary elements. The core elements constituted essential information required for safe resuscitation and disposition of the newborn. ${ }^{16}$

Recent research reports have suggested that missing information regarding one or more of the core content elements can potentially cause adverse outcomes for the newborn and/or the mother. ${ }^{17} 18$ To identify missing elements, after all handovers were coded using the clinical content framework, we evaluated each handover for content completeness and content relevance. Content completeness was evaluated based on the presence of core and ancillary elements in a neonatal handover. Content relevance was evaluated based on the appropriateness of specific ancillary content elements in a handover. For this, we used the paediatric resident's delivery note as our 'gold standard' for establishing the veracity of the verbal information.

The coding for the presence (or absence) and relevance (or irrelevance) of handover content was conducted in the following manner: when a core clinical content element was discussed during the handover, it was coded as being 'present'. For example, if a patient's $\mathrm{HIV} /$ hepatitis B was negative and this information was communicated during handover, it was coded as present.
Table 2 Content completeness and relevance framework that was used for coding.

\begin{tabular}{|c|c|c|}
\hline Element type & $\begin{array}{l}\text { Status during handover } \\
\text { discussion }\end{array}$ & Coding \\
\hline $\begin{array}{l}\text { Core clinical } \\
\text { content element }\end{array}$ & Discussed (eg, HIV status). & Present \\
\hline $\begin{array}{l}\text { Core clinical } \\
\text { content element }\end{array}$ & $\begin{array}{l}\text { Not discussed (eg, HIV status } \\
\text { not discussed). }\end{array}$ & Missing \\
\hline $\begin{array}{l}\text { Ancillary clinical } \\
\text { content element }\end{array}$ & $\begin{array}{l}\text { Relevant to the patient case } \\
\text { and discussed (eg, fetal } \\
\text { tracing discussed for a patient } \\
\text { with fetal bradycardia). }\end{array}$ & Present \\
\hline $\begin{array}{l}\text { Ancillary clinical } \\
\text { content element }\end{array}$ & $\begin{array}{l}\text { Relevant to the patient case } \\
\text { and not discussed (eg, fetal } \\
\text { tracing discussed for a patient } \\
\text { with fetal bradycardia). }\end{array}$ & Missing \\
\hline $\begin{array}{l}\text { Ancillary clinical } \\
\text { content element }\end{array}$ & $\begin{array}{l}\text { Not relevant to the patient } \\
\text { case and not discussed (eg, } \\
\text { drug urine screen for the } \\
\text { mother is not relevant when } \\
\text { there is no known history of } \\
\text { abuse). }\end{array}$ & Irrelevant \\
\hline
\end{tabular}

Similarly, when an ancillary content element was relevant to the patient, but was not discussed during the handover, it was coded as 'missing'. For example, fetal heart rate/ tracing was a relevant content element in cases where the fetus had bradycardia. In such a case, the fetal heart rate/ tracing content element was coded as missing, if it was not discussed. In cases where an ancillary content element was irrelevant (and was also not discussed), it was coded as 'irrelevant'. For example, maternal drug urine screen, if negative is not an essential core element and was not discussed during handover. Hence, it was coded as irrelevant (table 2).

A subset of the handovers was coded by a second physician $(n=10)$ with $98 \%$ of agreement for content completeness and with 99\% agreement for content relevance. Coding discrepancies were resolved through discussion.

\section{Adverse events}

Using information from the resident delivery note and handover communication, we investigated whether missing information could have caused potential adverse events. For this, the first author captured the following information from the resident delivery note: resuscitation events including type of resuscitation, Apgar scores and disposition of the newborn. Next, we determined if one or more of the missing (both core and ancillary) elements during the handover communication could have led to adverse outcomes, as represented by greater need for resuscitation, poor $5 \mathrm{~min}$ Apgar scores or unexpected disposition to the NICU for the newborn. For example, if antenatal acute haemorrhage was omitted from neonatal handover and the newborn needed full resuscitation, the unavailability of such information could have caused 


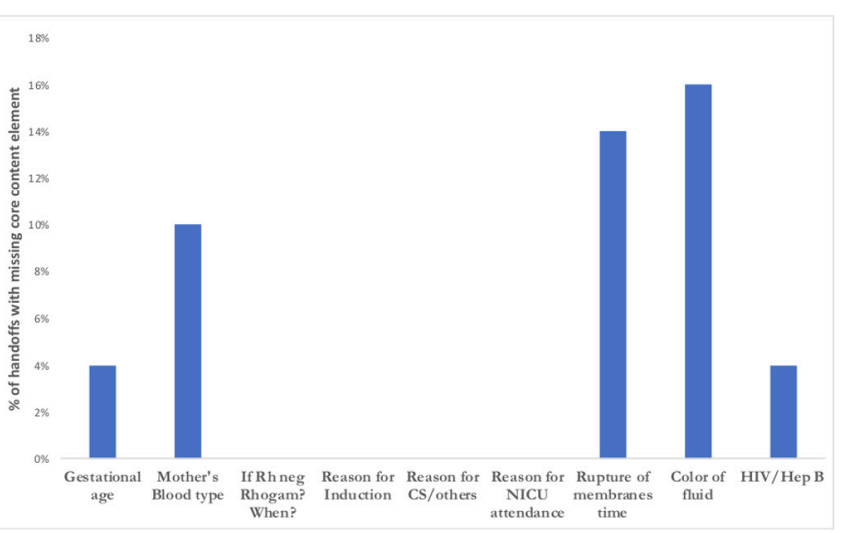

Figure 1 Percentage of handovers with missing core clinical consent elements. NICU, neonatal intensive care unit.

potential delays and unnecessary interventions, leading to potential adverse outcomes.

This coding was performed by the first author and a paediatric fellow using a subset of 10 cases. There was $90 \%$ agreement on the cases, and differences were resolved through discussion.

\section{Statistical analysis}

We computed descriptive statistics regarding the percentage of missing core and ancillary clinical content elements during handover communication. Next, using logistic regression, we estimated the odds of potential adverse outcomes based on the number of missing clinical content elements per patient. All analyses were performed using $\mathrm{R}$, and an alpha level of 0.05 was used.

\section{RESULTS}

Fifty-two per cent $(n=26)$ of the neonatal handovers had at least one missing clinical content element, with an average of 0.98 (median $=1, \mathrm{IQR}=0, \mathrm{SD}=1.15$ ) missing clinical content elements per handover. Thirty-two per cent $(n=16)$ of the handovers had one or more missing core clinical content elements, with an average of 0.48 $(\mathrm{SD}=0.81)$ missing core clinical content elements per handover.

The common core missing elements were colour of amniotic fluid $(16 \%, \mathrm{n}=8)$, time of the rupture of membrane $(14 \%, \mathrm{n}=7)$, mother's blood type $(10 \%, \mathrm{n}=5)$ and HIV/hepatitis B status (4\%, $\mathrm{n}=2)$. Among the ancillary clinical content elements, the rupture membrane type was missing in $12 \%(n=6)$ of the neonatal handovers (figure 1; online supplementary appendix table 1).

Based on the logistic regression, we found that with unit increase in the number of missing clinical content elements increased the odds of adverse events by 2.39 (95\% CI 1.18 to 5.37).

Interviews with the neonatal and $\mathrm{OB}$ teams highlighted the factors contributing to the high degree of missing information shared and its potential effects. Residents were dissatisfied by the content presented during handovers, describing it as of being 'poor quality' as they were often 'one-liners' with 'incomplete information'. They described their frustration with the inaccuracies in the presented information. One resident remarked that ' $\ldots a$ lot of the information is not clear. Sometimes the reason for NICU attendance is not clear and conflicting information provided by the baby nurse, mother's nurse and the $O B$ residents'. As a result, residents noted that they often do not fully rely on the presented information for their decision-making: ' $I$ don't go off of it, because it's been wrong, so often'.

Nurses attributed the poor quality of the handover content to three factors: limited time available for preparation, fragmentation information that was difficult to assemble in an efficient and quick manner and inconsistent use of information tools for aggregating or supporting handovers (table 3 ). These coupled with the lack of a structured process for handovers, led to considerable subjectivity in the organisation and varying presentation formats followed for handovers.

Nurses acknowledged that handover processes were 'inconsistent' and highlighted that at times information was simply not available. One nurse remarked that 'patient information sheets [are] not available all the time'; other times there is not enough time to look up things and as a result 'some things could be missed' and at other times the nurses rely on 'reading out the [information entered by the admitting nurse] on the antepartum assessment sheet, which is sometimes not updated'.

\section{DISCUSSION}

Based on an exploratory study of interservice, interprofessional handovers between $\mathrm{OB}$ and NICU teams, we found that $52 \%$ of the handovers missed one or more clinical content elements. In nearly a third of the handovers, at least one core clinical content element was not discussed, increasing potential for adverse events for both the mother and the newborn. In addition, not discussing clinical content elements during handovers increased the potential for adverse events by over twofold. The high percentage of handovers where one or more core clinical elements was not discussed increases the potential for acute or long-term complications and adverse outcomes. ${ }^{19}$ Residents and nurses attributed these communication failures to the lack of a formalised mechanism or protocol for capturing or sharing the handover content.

Perceptions of poor handover quality is reflective of the lack of shared understanding between $\mathrm{OB}$ nurses and neonatal physicians- a critical function of effective handover communication. ${ }^{2}{ }^{20}$ Our study findings highlight two fundamental issues that can impact the development of a shared understanding during neonatal handovers. First, there was mismatch between the expectations of the physicians and nurses regarding the information communicated during handovers. During handovers, OB nurses focused on maternal peripartum events and laboratory tests; although such information 
Table 3 Examples from interviews regarding the challenges faced by residents and nurses during handovers

\begin{tabular}{|c|c|c|}
\hline \multirow{2}{*}{$\begin{array}{l}\text { Barriers } \\
\text { Variability in handover } \\
\text { content }\end{array}$} & \multicolumn{2}{|c|}{ Root contributor(s) (with examples from the data) } \\
\hline & $\begin{array}{l}\text { Limited time available for } \\
\text { handover preparation. }\end{array}$ & $\begin{array}{l}\text { 'Limited time especially in urgent or crash CS (Cesarean Section). } \\
\text { Looking up stuff takes time'" (RN1). } \\
\text { 'If mom just comes and delivers then there is no time to look up } \\
\text { details in chart. I then read out the antepartum assessment sheet, } \\
\text { which is sometimes not updated' (RN2). }\end{array}$ \\
\hline & $\begin{array}{l}\text { Information is fragmented } \\
\text { and distributed in different } \\
\text { sources making access } \\
\text { difficult. }\end{array}$ & $\begin{array}{l}\text { 'Pregnancy summary report. Review of results, power notes, } \\
\text { antepartum assessment sheet. Information is at a lot of places' (RN1) } \\
\text { 'Tools helpful but they are scattered, most of the time. I have to look } \\
\text { at multiple places' (RN2). } \\
\text { 'There are a lot of sources which I have to access to get information } \\
\text { in the mother's chart' (RN3). }\end{array}$ \\
\hline & $\begin{array}{l}\text { Inconsistent use of tools for } \\
\text { handovers. }\end{array}$ & $\begin{array}{l}\text { 'Sometimes, they have their own list, some use antepartum } \\
\text { assessment sheet' (MD1). } \\
\text { 'Sometime there is no tool used' (MD2). } \\
\text { '[U]se antepartum sheet and add anything significant that happened' } \\
\text { (RN1). }\end{array}$ \\
\hline $\begin{array}{l}\text { Variability in the } \\
\text { handover process }\end{array}$ & $\begin{array}{l}\text { Inconsistencies in how } \\
\text { handover is conducted. }\end{array}$ & $\begin{array}{l}\text { 'Inconsistent, some people better at giving information' (MD1). } \\
\text { 'It is not consistent, dependent on who is giving the handoff' (MD6). } \\
\text { 'Not very consistent. I gown up, and sometimes sign-out is } \\
\text { whispered' (MD8). }\end{array}$ \\
\hline
\end{tabular}

was relevant and important for care activities, residents expected additional information-related fetal imaging (including cardiac and ultrasound findings) and anomalies, which are key for determining the disposition of the newborn.

Second, there was considerable subjectivity in the manner in which nurses prepared and organised information for handovers, owing to a variety of factors including lack of time, unavailability of information, differing expertise and experience of the nurses, differences in communication styles and the differences in the tools used (eg, antepartum sheet, maternal admission sheet or personal notes).

Both these factors point to the need for creating a structure to organise the content and process of neonatal handovers. Although patient safety organisations have standardisation goals for handovers, much of these efforts have been on shift-based handovers. ${ }^{13} 21$ Interservice, interprofessional handovers present a new and unique challenge for handovers. Structured and streamlined communication in time-pressured situations have been supported through the use of standardised approaches such as checklists in surgery, and air-traffic controller-pilot communication using standardised formats have been found to be remarkably successful. ${ }^{22}$ Such a standardised strategy was repeatedly highlighted by all participants as a feasible and robust mechanism to reduce the inconsistencies in neonatal handover content and process.

This study has several limitations. The study was conducted in a single academic hospital setting, and hence some of our findings may not be generalisable to other settings. We used a convenience sample of 50 neonatal handovers. However, handovers were analysed at a granular level and were supplemented with interviews and observations. Although the potential for adverse outcome measure was independently coded and verified, it is a subjective measure. Finally, we did not use patient-related or clinician-related covariates in the logistic regression analysis.

Contributors AA and JA conceived the study; AA collected the data. All authors were involved in the coding, analysis and interpretation of the results. All authors were involved in the drafting of the manuscript and approved the final version.

Funding The authors have not declared a specific grant for this research from any funding agency in the public, commercial or not-for-profit sectors.

Competing interests None declared.

Patient consent for publication Not required.

Ethics approval The Institutional Review Board approved this study and verbal consents were obtained from all participants.

Provenance and peer review Not commissioned; externally peer reviewed.

Data sharing statement This is a qualitative study, and therefore the data generated are not suitable for sharing beyond that contained within the report. Further information can be obtained from the corresponding author.

Open access This is an open access article distributed in accordance with the Creative Commons Attribution Non Commercial (CC BY-NC 4.0) license, which permits others to distribute, remix, adapt, build upon this work non-commercially, and license their derivative works on different terms, provided the original work is properly cited, appropriate credit is given, any changes made indicated, and the use is non-commercial. See: http://creativecommons.org/licenses/by-nc/4.0/.

\section{REFERENCES}

1. Abraham J, Kannampallil TG, Patel VL. Bridging gaps in handoffs: a continuity of care based approach. J Biomed Inform 2012;45:240-54.

2. Abraham J, Kannampallil T, Patel VL. A systematic review of the literature on the evaluation of handoff tools: implications for research and practice. J Am Med Inform Assoc 2014;21:154-62.

3. The Joint Commission. Sentinel Event Data Event Type by Year 1995 - 2015. 2015. Jul 2017 https://www.jointcommission.org/assets/1/ 18/Event_Type_by_Year_1995-2015.pdf 
4. Abraham J, Reddy MC. Challenges to inter-departmental coordination of patient transfers: a workflow perspective. Int J Med Inform 2010;79:112-22.

5. Apker J, Mallak LA, Applegate EB, et al. Exploring emergency physician-hospitalist handoff interactions: development of the Handoff Communication Assessment. Ann Emerg Med 2010;55:161-70.

6. Hilligoss B, Cohen MD. The unappreciated challenges of betweenunit handoffs: negotiating and coordinating across boundaries. Ann Emerg Med 2013;61:155-60.

7. Wyckoff MH, Aziz K, Escobedo MB, et al. Part 13: Neonatal Resuscitation: 2015 American Heart Association Guidelines Update for Cardiopulmonary Resuscitation and Emergency Cardiovascular Care. Circulation 2015;132(18 Suppl 2):S543-60.

8. Vanderbilt AA, Pappada SM, Stein $\mathrm{H}$, et al. Increasing patient safety with neonates via handoff communication during delivery: a call for interprofessional health care team training across GME and CME. Adv Med Educ Pract 2017;8:365-7.

9. Boyd AD, Dunn Lopez K, Lugaresi C, et al. Physician nurse care: A new use of UMLS to measure professional contribution: Are we talking about the same patient a new graph matching algorithm?. Int J Med Inform 2018;113:63-71.

10. Friesen MA, White SV, Byers JF. Handoffs: Implications for Nurses. In: Hughes RG, ed. Patient Safety and Quality: An Evidence-Based Handbook for Nurses. Rockville (MD), 2008.

11. Keenan W, López M, Niermeyer S. Delivery and Immediate Neonatal Care $A A P, 2018$.
12. Strauss A, Corbin JM. Basics of qualitative research: Grounded theory procedures and techniques. Sage 1990.

13. Abraham J, Kannampallil TG, Almoosa KF, et al. Comparative evaluation of the content and structure of communication using two handoff tools: implications for patient safety. J Crit Care 2014;29:311.e1-311.e7.

14. Dadiz R, Weinschreider J, Guillet R, et al. The Delivery Room Communication Checklist. MedEdPORTAL 2014;10:9797.

15. Dadiz R, Weinschreider J, Schriefer J, et al. Interdisciplinary simulation-based training to improve delivery room communication. Simul Healthc 2013;8:279-91.

16. AAo P. Textbook of Neonatal Resuscitation (NRP). 7th Edition, 2016.

17. Gephart SM. The art of effective handoffs: what is the evidence? Adv Neonatal Care 2012;12:37-9.

18. Sundgren NC, Kelly FC, Weber EM, et al. Improving communication between obstetric and neonatology teams for high-risk deliveries: a quality improvement project. BMJ Open Qual 2017;6:e000095.

19. Miller Jr DW, Yeast JD, Evans RL. Missing prenatal records at a birth center: A communication problem quantified. Washington DC: AMIA Annual Symposium Proceedings, 2005.

20. Patterson ES, Wears RL. Patient handoffs: standardized and reliable measurement tools remain elusive. Jt Comm J Qual Patient Saf 2010;36:52-61.

21. Abraham J, Nguyen V, Almoosa KF, et al. Falling through the cracks: information breakdowns in critical care handoff communication. AMIA Annu Symp Proc 2011;2011:28-37.

22. Gawande A. The Checklist Manifesto. India: Penguin Books, 2010. 